\title{
Investigating the Impact of Multiple Competition on Producer Pricing in the Food Industry
}

\author{
Negin Deljouyan Davood Jafari* Asghar Darigh \\ Department of Industrial Engineering,College of Engineering,Parand Islamic Azad \\ University,Parand,Tehran,Iran
}

\begin{abstract}
Pricing is one of the most important and strategic decisions in the supply chain and can be called as one of the leading management arts. Pricing can have a huge impact on the sale of goods or services. One of the product pricing branches is the pricing of food products, which is of particular importance due to the particular circumstances of this market. Food products have a significant sensitivity due to the nature of corruption, the highly competitive nature of the industry, and the direct relationship with different consumer groups with different levels of income.In this study, two producers and two retailers were considered, one of these producers having a monopolistic market and the other having a multi-competitive market. The producer who has a monopolistic market only sends products to his retailer and the manufacturer with multiple competitive send goods to both retailers. In addition, the two scenarios are defined in a way that the first scenario is without green service and the second scenario applied green service. The first manufacturer only has the market of the first retailer and second-manufacturer hasboth the first and second-party retailers. Then the model was solved for different strategies and optimal strategies for each side of the chain were identified. Finally, numerical issues were presented, solved and analyzed in different dimensions.
\end{abstract}

Keywords: pricing, food products, competition, government policy, game theory.

DOI: $10.7176 /$ IEL/9-4-05

Publication date:May $31^{\text {st }} 2019$

\section{Introduction}

Pricing is one of the most important and strategic decisions in the supply chain, and it can be called one of the leading management arts. Pricing can have a huge impact on the sale of goods or services. Today, any system is bound to make optimal pricing decisions because a firm must provide a price that can also generate revenues proportional to the value offered to the customer, as well as their position to customers of complementary goods, competitors and new potential entrants (De Trilevel et al., 2004). Pricing is one of the tools of the organization to provide customer satisfaction, control demand and increase profitability. Price is a point of connecting the customer's mentality and supply activities (from construction to sales), because in many cases the customer consume pricing as a key factor in determining the quality or obtaining additional information that they accumulate extremely time-consuming. (eternally and agrowal, 2005). Price is one of the most flexible business tools that can generate revenue.

Demand for products is heavily dependent on the price of sales of that product, the price of competitors, and so on. Therefore, you can say that by choosing the right pricing strategy, demand will increase. In addition, in modern business environments, the sale of credit by the manufacturer is used as a means of attracting the buyer to buy more volumes of goods in order to earn profits (Tangam and Otayakomar, 2009).

In the past, pricing was done by rule of thumb, taking into account the head-to-head price, plus some profits matching the product type. However, today, due to the competitive environment, that dominates the business environment, traditional and subjective approaches cannot be used for dominant goods and services (Ki and Bai, 2017).

Pricing, regardless of factors influencing it, cannot provide real-world answers. In fact, for the purpose of pricing goods or services, it is necessary to try to consider as much important factors as possible and, in this respect, the pricing being done is most in line with the real world (Kay and Bai, 2017). As we said, there are many factors affect pricing. Here are some things to note:

Monopoly: If a company in the market produces a single product or only has a significant competitor, the pricing policy of the company will undergo major changes. In this situation, the company feels free to act in the price range because it does not see a serious rival in the market. Hence, monopoly in the consumer goods market is detrimental to consumers and has a major impact on the price offered by the manufacturer (Kay and Bai, 2017).

Competition and Collaboration: Competition and collaboration today have become more wide spread and common concepts in supply chain management. Tools such as game theory have been developed to analyze interactions in a supply chain so that each member of the chain can have a promotional program for itself, but an interactive relationship, that is, a winning board, occurs when each one is able to select a partner for them to cover part of the advertising costs. The expansion of the volume of business and the increasing complexity of 
retail sales require a change in the approach to advertising. Today, retailers find a lot of power and play a more active role in customer relationship due to the increased complexity of the competition. Participatory advertising is one of the solutions that manufacturers and distributors can share in promotional programs. This not only reduces the cost of advertising but also creates an important link with local retailers and brings better brand performance. Collaboration in promotions is an agreement in which a manufacturer agrees to pay a portion or all of the cost of local promotions by a retailer. The theory of games is a tool used to solve this problem without collaboration and cooperation, which takes into account the successive or simultaneous decisions of several actors (Chaab and Rasti Bazaki, 2016).

Government policy: In some countries, and especially in less developed countries, the government plays a very important role in determining and policy on certain products. Especially for consumable and applicable goods such as food products. The government, with direct pricing or policies such as reducing or increasing import tariffs, or imposing a price command for some commodities, is practically affecting on the price offered for commodities.

Different approaches have been proposed for pricing, one of the most important and most used of them is the theory of games approach. The game theory has been used as one of the most widely used approaches to pricing products and services (Abdoli, 2012):

- Taking into account the strategic situation or in a game in which the success of the person in choosing is dependent on the choice of others

- Considering the conditions of interest and cooperation

- More flexibility than mathematical modeling techniques in the context of considering different factors

- The possibility of modeling and making decisions in the absence of incomplete information

Pricing is used in a variety of areas such as:

- Industrial products pricing

- $\quad$ Service pricing

- $\quad$ Food pricing

- $\quad$ Energy pricing

$\bullet$

One of the product pricing branches is the pricing of food products, which is of particular importance due to the particular circumstances of this market. Food products have a significant sensitivity due to the nature of corruption, the highly competitive nature of the industry, and the direct relationship with different consumer groups with different levels of income. In other words, the pricing of these items is different from the pricing of other products and services, which consider them to improve the decisions made in this area.

One of the most important researches in the field of present study is the Barki Paper (2016). In this paper, the theory of games was used to determine the optimal price of goods in terms of competition and advertising in the supply chain. In this research, a game theory approach was considered to be incomplete dynamic information. In this regard, four possible game structures, including Nash equilibrium, Stockterg retailer, Stoccelerg producer and co-worker player, were presented. The above research can be improved by taking into account certain conditions, although superior to other similar studies. One of these is the specifying a model for a particular product, as well as considering some macroeconomic parameters. Specifying a model for a particular product can result in more functional and more accurate results. On the other hand, taking into account macroeconomic parameters can lead to a closer approach to real-world conditions and consider the impact of macroeconomic parameters that affect product pricing.

Thus, in this research, in completing the research in the subject matter of the research, aspects of a combination of issues affecting food pricing are considered to provide a model for more adaptation to real-world conditions. For this purpose, in this research, food pricing is modeled in terms of competition as well as government policy using game theory. By modeling this issue, there are good tools available to decision makers in the food industry to take into account the factors that affect their products' pricing. In this context, a study that was carried out in 2016 by Sha'b and Razi Brzaki could be promising and provided ideas for the intended expansion of research. In particular, the study seeks to examine the effects of competition and government policy on food prices. The main variables in the current research are the optimal producer and retailer prices for the product.

In this research, the Rasti Barzaki and Chaab (2016) is used. For this reason, this section discusses the parameters and model variables of this paper.

\section{parameters:}

$\alpha$ : potential price demand

$\beta$ : price sensitivity

$v$ : shape parameter

$\gamma$ : Effectiveness of local advertising 
$\delta$ : The effectiveness of national advertising

A: unsaturated sales

B: AdSense sensitivity

$\mathrm{C}$ : unit cost of the manufacturer

$\mathrm{d}$ : the cost of the retail unit of the retailer

Decision variables:

w: retail price

q: National Promotion

$\mathrm{t}$ : producer participation rate

p: retail price

m: margin of retail profit

a: Local advertising

$\Pi_{M}:$ producer profits

$\Pi_{R}$ : Retail profits

$\Pi_{R}$ : System profits

In this study, there is a two-tier chain that a producer of his product sells to a retailer who also sells the product to the final customer. The consumer demand function depends on marketing efforts and retail prices, as shown in the literature of the subject:

$\mathrm{V}(\mathrm{p}, \mathrm{a}, \mathrm{q})=\mathrm{g}(\mathrm{p}) \mathrm{S}(\mathrm{a}, \mathrm{q})$

In such a way that the function of the advertising-sales relation is determined by the following relationship:

$\mathrm{S}(\mathrm{a}, \mathrm{q})=\mathrm{A}-\mathrm{B} a^{-\gamma} q^{-\delta}$

Which indicates an incremental and convex relationship. Also, the demand function in terms of price is as follows:

$\mathrm{g}(\mathrm{p})=(\alpha-\beta \mathrm{p})^{\frac{1}{v}}$

So we will have:

$\mathrm{V}(\mathrm{p}, \mathrm{q}, \mathrm{a})=(\alpha-\beta \mathrm{p})^{\frac{1}{v}}\left(\mathrm{~A}-\mathrm{B} a^{-\gamma} q^{-\delta}\right)$

In order to satisfy the assumptions of the profit balance, the new decision variable using the $\mathrm{m}$ as the profit margin of the retailer is obtained as follows:

$\mathrm{m}=\mathrm{p}-\mathrm{w}$

Finally, the producer, retailer, and system profits are derived from the following relationships, respectively:

$\Pi_{M}=(\mathrm{w}-\mathrm{c})(\alpha-\beta(\mathrm{m}+\mathrm{w}))^{\frac{1}{v}}\left(\mathrm{~A}-\frac{B}{\alpha^{\gamma} q^{\delta}}\right)-\mathrm{ta}-\mathrm{q}$

$\Pi_{R}=(\mathrm{m}-\mathrm{d})(\alpha-\beta(\mathrm{m}+\mathrm{w}))^{\frac{1}{v}}\left(\mathrm{~A}-\frac{B}{\alpha^{\gamma} q^{\delta}}\right)-(1-\mathrm{t}) \mathrm{a}$

$\Pi_{M+R}=(\mathrm{p}-(\mathrm{c}+\mathrm{d}))(\alpha-\beta(\mathrm{m}+\mathrm{w}))^{\frac{1}{v}}\left(\mathrm{~A}-\frac{B}{\alpha^{\gamma} q^{\delta}}\right)-\mathrm{a}-\mathrm{q}$

In order to avoid the negative effect of the demand function, the following conditions should exist:

$\mathrm{V}(\mathrm{p}, \mathrm{a}, \mathrm{q})>0 \rightarrow \mathrm{p}<\frac{\alpha}{\beta}$ or $\mathrm{w}<\frac{\alpha}{\beta}-\mathrm{m}, \mathrm{A}-\frac{B}{\alpha^{\gamma} q^{\delta}} \geq 0, \mathrm{w}>c, \mathrm{~m}>d, \mathrm{p}>c+d$

After providing the retail profit, manufacturer and system functions, the problem is solved. In this regard, four game structures including Nash equilibrium, Steckleberg retailers, Steckleberg producer and collaborative games were presented and the results for each strategy were explained.

In this research, a model is based on the theory of competitive games using Nash equilibrium and in the presence of a retailer. Considering the effects of government competition and policy on the issue, it is hoped that a model will be presented to meet the real world requirements and be used by managers and practitioners in the food industry.

\section{Research Methodology}

The present study is specifically implemented for case studies at Pegah Dairy Company in Tehran. Therefore, the final step of this study is to implement a research model on a case study in Tehran Pegah Dairy Company.

Figure 1 shows the steps taken by the exploration. 


\section{Review the literature of research \\ Design the research model \\ Numerical design \\ Numerical tests \\ Conclusion}

Figure 1. The research framework

\section{3-5- Problem Statement}

\section{3-5-1- An explanation of the problem}

There are two manufacturers and two retailers in the study, one of which has a monopolistic market and the other with a multi-competitive market, and the manufacturer who has a monopolistic market sends only his own retailer, and the producer It offers both retailers with multiple competitive breeding grounds. In addition, the two scenarios are defined as the first scenario without green service and the second scenario with green service, which after obtaining optimal quantities of the major producer price, retailer price, etc., provides numerical examples and compares two The scenario is dealt with.

The first manufacturer only has the first and second-largest retailers, both the first and second-party retailers. Figure 2. shows the structure of the problem under study. As is clear from this form, the problem is examined in the presence of two producers and two retailers.

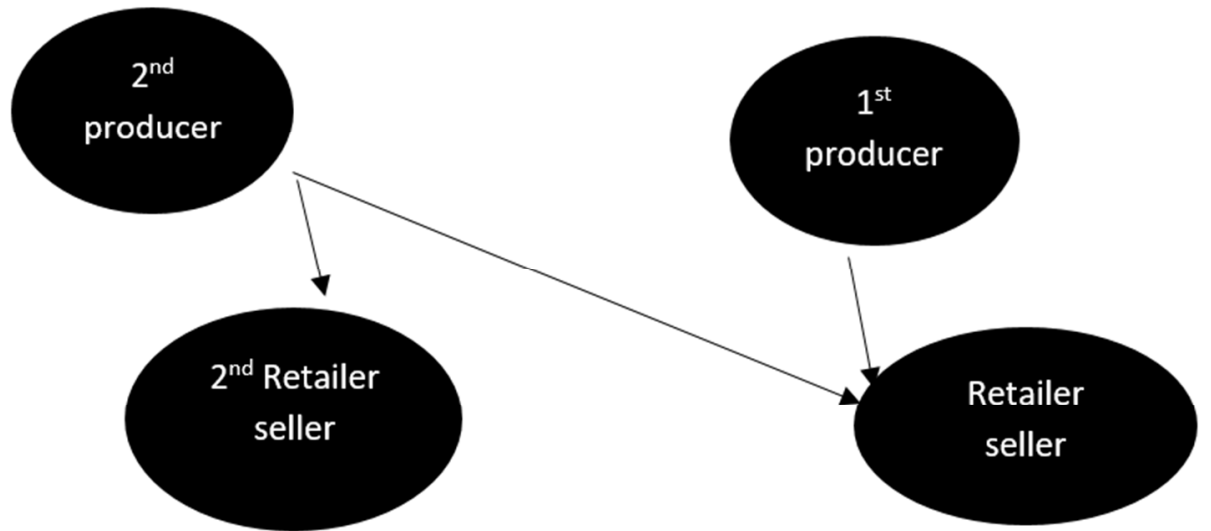

Figure 2. The structure of the problem under consideration

The assumptions of the research model are as follows:

- The demand equation is taken linearly.

- Supply chain has two levels of retailer and manufacturer.

- Each level of supply chain has two parts.

- Costs are considered throughout the fixed planning horizon.

- All parameters of the definite problem are considered.

\section{3-5-2 Designing problem scenarios}

Designing and solving games in a competitive environment is based on the design of strategies that affect the playing field. Based on these scenarios, different modes of play are formed, based on which equilibrium equations and related calculations are performed. Therefore, the design of scenarios is very important in game theory issues, because they form a large part of the various modes and calculations of the game.

In this study, in order to examine the impact of government policies, we considered two main scenario categories for the problem:

1. The scenario without providing green services to producers

2. Scenario by providing green services to producers

In fact, in this research, government policy is shaped by considering the requirement for compliance with environmental laws, and so-called green production. In the second scenario, which is a scenario with the provision of green services by producers, considering the green service level parameter, the impact of the green supply chain requirements has been studied in the problem.

Of course, different scenarios can be considered in the present study, such as a leadership-based scenario, supply chain compliance, monopoly-competitive scenario, and so on. Therefore, in the present study, 
considering the purpose of the study, considering the impact of government policies, two scenarios concerning the implementation of the green production policy or its non-implementation were considered and based on which different situations were defined and analyzed Placed.

\section{3-6 Research Model}

In this section, based on various scenarios, we write different equations in order to calculate the optimal values of the research variables. In fact, considering the two main scenarios without providing green services and providing green services, demand equations, retailers' profits and wholesaler prices are presented. Then, by analyzing these equations, the optimal value of retailers' prices as well as the optimal price of wholesalers is determined.

Therefore, in the remainder of this section, equations and then the optimal values are presented, taking into account two scenarios without providing green services and providing green services.

\section{Scenario A) without providing green services to factories}

\section{Calculate the demand equation}

The demand equation (retailer order quantity or factory production amount) was considered as a linear function:

$$
y_{i j}=a_{i j}+b_{i j} p_{i j}
$$

aij: potential market size (maximum product demand even if its price is zero)

bij: self-priced demand stretch (demand factor relative to product price changes)

Pij: Retail price

yij: The amount of goods sent from the manufacturer i to the $\mathrm{j}$ retailer (demand)

\section{Calculate the optimal amount of the first and second retailer prices}

In this section, the optimal retail sales price and the second retailer are obtained based on the general equilibrium of retail profit, calculated in MATLAB software:

The general equation of profit for the first retailer:

As the first retailer comes from the first manufacturer (which owns the first-person retail market) and the secondgeneration product, we have:

(2) $\pi_{R 1}=\left(p_{11}-w_{1}\right) \cdot y_{11}+\left(p_{21}-w_{2}\right) \cdot y_{21}$

Since the first manufacturer has a monopoly on the primary retailing market, the general price of the producer is the same as the retailer's price, instead of $\left(p_{11}-w_{1}\right)$ the same amount of producer of the plant, where $\mathrm{Ci}$ is the cost of producing the factory I $\left(p_{11}-c_{1}\right)$ :

(3) $\pi_{R 1}=\left(p_{11}-c_{1}\right) \cdot y_{11}+\left(p_{21}-w_{2}\right) \cdot y_{21}$

* The general equation of profit of the second retailer:

As the first producer (which owns the first-person retailer's market) cannot give the second retailer, then the second retailer will only take the second production, thus:

(4) $\pi_{R 2}=\left(p_{22}-w_{2}\right) \cdot y_{22}$

\section{* Calculate the first retail price (wholesale price) and the second retailer's price:}

First, we derive the first (3) retail profit equation versus p11 and p21 so that we can obtain the first retail price for products numbered 1 and 2 :

(5) $\partial \pi_{R 1} / \partial p_{11}=a_{11}-b_{11} \cdot p_{11}+b_{11} \cdot\left(c_{1}-p_{11}\right)=0$

$\partial \pi_{R 1} / \partial p_{21}=a_{21}-b_{21} \cdot p_{21}+b_{21} \cdot\left(p_{21}-w_{2}\right)=0$

From the above equations, we obtain the optimal values of p11 and p21:

(6) $p_{11}=\left(a_{11}+b_{11} \cdot c_{1}\right) / 2 b_{11}$

(7) $p_{21}=\left(a_{21}+b_{21} \cdot w_{2}\right) / 2 b_{21}$

Now we derive from the second-party profit margin equation (2) compared to $\mathrm{p} 22$, so that we can obtain the optimal second-party retailer's price for products number 1 and 2 :

(8) $\partial \pi_{R 2} / \partial p_{22}=a_{22}-b_{22} \cdot p_{22}-b_{22} \cdot\left(p_{22}-w_{2}\right)=0$

The optimal value of $\mathrm{p} 22$ is equal to:

(9) $p_{22}=\left(a_{22}+b_{22} \cdot w_{2}\right) /\left(2 b_{22}\right)$ 
3- Calculate the optimal amount of the wholesale price of the first and second factory

* The general equation of the wholesale prices of the first and second manufacturer

Since the main price at the factory is equal to the same retail price, $\left(p_{11}-c_{1}\right)=\left(p_{11}-w_{1}\right)$ then we have:

(10) $\mu_{f 1}=\left(p_{11}-c_{1}\right) \cdot y_{11}$

The major selling price in the second producer is:

(11) $\mu_{f 2}=\left(w_{21}-c_{2}\right) \cdot\left(y_{21}+y_{11}\right)$

* Calculate the main producer price (wholesale price) and the major producer price of the second:

If we derive from the first manufacturer $\mathrm{p} 11$, and the sales price is the equation (6) we have:

(12) $w_{1}=p_{11}=\left(a_{11}+b_{11} \cdot c_{1}\right) / 2 b_{11}$

In order to determine the major selling price of the second producer, we derive equation (11) from w2:

(14) $w_{2}=\left(a_{21}+a_{22}+b_{21} \cdot c_{1}+b_{22} \cdot c_{2}\right) /\left(2 b_{21}+2 b_{22}\right)$

Scenario b) Providing green service providers

1. Calculation of the demand equation

The demand equation (retail order quantity of factory production) was considered as a linear function

$y_{i j}=a_{i j}+b_{i j} p_{i j}+\alpha_{i} \theta_{i}$

That:

$\theta_{i}:$ Green service level

2. Calculate the optimal amount of the first and second retailer prices

In this section, we get the optimal price for the first retailer and the second retailer based on the general equilibrium of retail profit, we calculate in the mathematical software.

* The general equation of profit for the first retailer:

As the first retailer comes from the first manufacturer (which owns the first-person retail market) and the secondgeneration product, we have:

$$
\pi_{R 1}=\left(p_{11}-w_{1}\right) \cdot y_{11}+\left(p_{21}-w_{2}\right) \cdot y_{21}
$$

(17) $\pi_{R 1}=\left(p_{11}-w_{1}\right) \cdot\left(a_{11}-b_{11} p_{11}+\alpha_{1} \theta_{1}\right)+\left(p_{21}-w_{2}\right) \cdot\left(a_{21}-b_{21} p_{21}+\alpha_{2} \theta_{2}\right)$

Since the first manufacturer has monopolized the primary retailing market, the main producer price is the same as the retailer's price; instead of $\left(w_{1}-c_{1}\right)$ we put the same amount of factory producer $\left(p_{11}-c_{1}\right)$, where $\mathrm{Ci}$ is the cost of producing the i-th plant.

(18) $\pi_{R 1}=\left(p_{11}-c_{1}\right) \cdot\left(a_{11}-b_{11} p_{11}+\alpha_{1} \theta_{1}\right)+\left(p_{21}-w_{2}\right) \cdot\left(a_{21}-b_{21} p_{21}+\alpha_{2} \theta_{2}\right)$

* The general equation of profit of the second retailer:

As the first manufacturer (which owns the first retail retailer's market) cannot give the second retailer, then the second reciprocity only comes from the second generation of goods, then we have:

(19) $\pi_{R 2}=\left(p_{22}-w_{2}\right) \cdot y_{22}$

(20) $\pi_{R 2}=\left(p_{22}-w_{2}\right) \cdot\left(a_{22}-b_{22} p_{22}+\alpha_{2} \theta_{2}\right)$

* Calculation of the first retail price (wholesale price) and the second retailer's price:

In order to determine the optimal price of the first retailer, first we derive from the first-profit profit equation for p11 and p21:

$$
\begin{aligned}
& \text { (21) } \partial \pi_{R 1} / \partial p_{11}=a_{11}-b_{11} \cdot p_{11}+\alpha_{1} \cdot \theta_{1}+b_{11} \cdot\left(c_{1}-p_{11}\right)=0 \\
& \partial \pi_{R 1} / \partial p_{21}=a_{21}-b_{21} \cdot p_{21}+\alpha_{2} \cdot \theta_{2}+b_{21} \cdot\left(p_{21}-w_{2}\right)=0
\end{aligned}
$$

From the above equations, we obtain the values of p11 and p21:

(23) $p_{11}=\left(a_{11}+b_{11} \cdot c_{1}+\alpha_{1} \cdot \theta_{1}\right) / 2 b_{11}$

(24) $p_{21}=\left(a_{21}+b_{21} \cdot w_{2}+\alpha_{2} \cdot \theta_{2}\right) / 2 b_{21}$

In order to determine the price of the second retailer, we derive the second-half profit margin equation with p22 
and obtain the value of $\mathrm{p} 22$ :

(25)

$$
\partial \pi_{R 2} / \partial p_{22}=a_{22}-b_{22} \cdot p_{22}+\alpha_{2} \cdot \theta_{2}-b_{22} \cdot\left(p_{22}-w_{2}\right)=0
$$

That p22 is equal to:

(26) $p_{22}=\left(a_{22}+b_{22} \cdot w_{2}+\alpha_{2} \cdot \theta_{2}\right) /\left(2 b_{22}\right)$

3. Calculation of the optimal quantity of the first and second factory wholesale prices

* The general equation of the wholesale prices of the first and second manufacturer

Since the main price at the factory is equal to the same retail price, $\left(w_{1}-c_{1}\right)=\left(p_{11}-c_{1}\right)$ then we have:

$$
\text { (27) } \begin{aligned}
\mu_{f 1} & =\left(p_{11}-c_{1}\right) \cdot y_{11}-I_{1} \cdot \theta_{1}^{2} / 2 \\
{ }_{(28)} & \mu_{f 1}=\left(p_{11}-w_{1}\right) \cdot\left(a_{11}-b_{11} p_{11}+\alpha_{1} \theta_{1}\right)-I_{1} \cdot \theta_{1}^{2} / 2
\end{aligned}
$$

That $I_{i}$ is the factory investment parameter for green services.

The major selling price in the second producer is:

$$
\begin{aligned}
& \mu_{f 2}=\left(w_{21}-c_{2}\right) \cdot\left(y_{21}+y_{11}\right)-I_{2} \cdot \theta_{2}^{2} / 2 \\
& \mu_{f 2}=\left(w_{21}-c_{2}\right) \cdot\left(\left(a_{22}-b_{22} p_{22}+\alpha_{2} \theta_{2}\right)+\left(a_{21}-b_{21} p_{21}+\alpha_{2} \theta_{2}\right)\right)-I_{2} \cdot \theta_{2}^{2} / 2
\end{aligned}
$$

*Calculation of the main producer price (wholesale price) and the major producer price of the second:

In order to calculate the first major price of the first manufacturer $\theta_{1}$, we derive from $\mathrm{p}_{-} 11$ and we obtain:

(31) $\partial \mu_{f 1} / \partial \theta_{1}=-\left(I_{1} / \theta_{1}\right)-\left(\alpha_{1} \cdot\left(c_{1}-p_{11}\right)\right)=0$

(32) $\theta_{1}=\alpha_{1} \cdot\left(c_{1}-p_{11}\right) / I_{1}$

Now we put $\theta_{1}$ in the equation (21) and get p11, which we have:

$$
\begin{aligned}
& p_{11}=\frac{\left(-c_{1} \cdot \alpha_{1}^{2}+I_{1} \cdot a_{11}+I_{1} \cdot b_{11} \cdot c_{1}\right)}{\left(-\alpha_{1}^{2}+2 I_{1} b_{11}\right)} \\
& \theta_{1}=\frac{-\left(\alpha_{1}\left(c_{1}+\frac{-\left(-c_{1} \alpha_{1}^{2}+I_{1} \cdot a_{11}+I_{1} \cdot b_{11} \cdot c_{1}\right)}{\left(-\alpha_{1}^{2}+2 I_{1} b_{11}\right)}\right)\right)}{I_{1}}
\end{aligned}
$$

In order to determine the major selling price of the second producer, we derive from equation (27) relative to w2 and we obtain the main selling price of the second producer:

(35) $\partial \mu_{f 2} / \partial w_{2}=\left(a_{21} / 2\right)+\left(a_{22} / 2\right)+\left(\alpha_{2} \cdot \theta_{2}\right)-\left(b_{21} \cdot w_{2} / 2\right)+\left(c_{2}-w_{2}\right)\left(\left(b_{21} / 2\right)+\left(b_{22} / 2\right)\right)=0$

(36) $\partial \mu_{f 2} / \partial \theta_{2}=-\left(I_{2} / \theta_{2}\right)-\left(a_{2} \cdot\left(c_{2}-w_{2}\right)\right)=0$

$$
w_{2}=\frac{\left(\frac{a_{21}}{2}+\frac{a_{22}}{2}+c_{2} \cdot\left(\frac{b_{21}}{2}+\frac{b_{22}}{2}\right)-\frac{\alpha_{2}^{2} c_{2}}{I_{2}}\right)}{\left(\frac{-\alpha_{2}^{2}}{I_{2}}+b_{21}+b_{22}\right)}
$$

$$
=\frac{-\left(\alpha_{2} \cdot\left(c_{2}+\frac{-\left(\frac{a_{21}}{2}+\frac{a_{22}}{2}+c_{2} \cdot\left(\frac{b_{21}}{2}+\frac{b_{22}}{2}\right)-\frac{\alpha_{2}^{2} c_{2}}{I_{2}}\right)}{2}\right)\right)}{\left(\frac{-\alpha_{2}^{2}}{I_{2}}+b_{21}+b_{22}\right)}
$$




$$
\left(a_{21}+\frac{\left(b_{21} \cdot\left(\frac{a_{21}}{2}+\frac{a_{22}}{2}+c_{2} \cdot\left(\frac{b_{21}}{2}+\frac{b_{22}}{2}\right)-\frac{\alpha_{2}^{2} c_{2}}{I_{2}}\right)\right)}{\left(\frac{-\alpha_{2}^{2}}{I_{2}}+b_{21}+b_{22}\right)}+\frac{-\left(-\alpha_{2}^{2}\left(c_{2}+\frac{-\left(\frac{a_{21}}{2}+\frac{a_{22}}{2}+c_{2} \cdot\left(\frac{b_{21}}{2}+\frac{b_{22}}{2}\right)-\frac{\alpha_{2}^{2} \cdot c_{2}}{I_{2}}\right)}{\left(\frac{-\alpha_{2}^{2}}{I_{2}}+b_{21}+b_{22}\right)}\right)\right.}{I_{2}}\right)
$$

$p_{21}=$

$\left(2 . b_{21}\right)$

$$
\left(a_{22}+\frac{\left(b_{22} \cdot\left(\frac{a_{21}}{2}+\frac{a_{22}}{2}+c_{2} \cdot\left(\frac{b_{21}}{2}+\frac{b_{22}}{2}\right)-\frac{\alpha_{2}^{2} c_{2}}{I_{2}}\right)\right)}{\left(\frac{-\alpha_{2}^{2}}{I_{2}}+b_{21}+b_{22}\right)}+\frac{-\left(-\alpha_{2}^{2}\left(c_{2}+\frac{-\left(\frac{a_{21}}{2}+\frac{a_{22}}{2}+c_{2} \cdot\left(\frac{b_{21}}{2}+\frac{b_{22}}{2}\right)-\frac{\alpha_{2}^{2} \cdot c_{2}}{I_{2}}\right)}{\left(\frac{-\alpha_{2}^{2}}{I_{2}}+b_{21}+b_{22}\right)}\right)\right.}{I_{2}}\right)
$$

So, in this section, we were able to identify, in the two strategies with and without green policy by the manufacturers, the optimal retail prices, as well as the optimal prices of the wholesaler or producer in the supply chain investigated in the research. By determining the optimal price for the manufacturer and the retailer, the chain components can offer the best price in order to maximize their profit function so that they can succeed and profit in the competitive environment they are operating in.

Nevertheless, the issues presented in this chapter were expressed in theoretical terms. Therefore, in order to evaluate the efficiency of the proposed model, it is necessary to apply numerical analysis and real-world problem solving using the above-mentioned approach. Hence, in the next chapter, the issue of numerical issues in different aspects and a case study of the Pekhma Dairy Company will be discussed.

\section{Results}

\section{Sensitivity analysis}

In this section, an analysis of the sensitivity of factory production costs is made and the effect of changes in parameters on the variables of the research is measured. To do this, issue number 3 is considered as base. To do this, the changes made to the variables are evaluated by changing a parameter and keeping other parameters constant.

In order to analyze the sensitivity to the factory production cost parameter, this parameter for the first manufacturer in issue number 3 is initially decreased by 0.25 and then increased by 0.25 and the effect of these changes on variables is examined.

\begin{tabular}{|c|c|c|c|c|c|c|c|c|c|}
\hline Parameters & $\bullet$ & $\begin{array}{c}\text { First } \\
\text { scenario }\end{array}$ & $\bullet$ & Second scenario & $\bullet$ & $\begin{array}{l}\text { first } \\
\text { Scenario } \\
(\%) \text { changes }\end{array}$ & $\bullet$ & $\begin{array}{c}\text { Second } \\
\text { Scenario } \\
(\%) \text { changes }\end{array}$ & $\bullet$ \\
\hline$p_{11}$ & $\cdot$ & 1026.25 & $\bullet$ & 102808 & $\bullet$ & $\begin{array}{r}0.845 \\
\text { decrease }\end{array}$ & • & $\begin{array}{r}0.841 \\
\text { decrease }\end{array}$ & $\bullet$ \\
\hline$p_{21}$ & - & 2138.57 & $\bullet$ & 214.342 & $\bullet$ & 0 & $\bullet$ & 0 & $\bullet$ \\
\hline$p_{22}$ & - & 201 & $\bullet$ & 201.607 & $\bullet$ & 0 & $\bullet$ & 0 & $\bullet$ \\
\hline$w_{1}$ & $\cdot$ & 1026.25 & $\bullet$ & 102.88 & $\bullet$ & $\begin{array}{r}0.845 \\
\text { decrease } \\
\end{array}$ & $\begin{array}{l}\bullet \\
\bullet\end{array}$ & 0.841 & $\bullet$ \\
\hline$w_{2}$ &. & 14.2 & $\bullet$ & 142.357 & $\bullet$ & 0 & $\bullet$ & decrease 0 & $\bullet$ \\
\hline$\pi_{R 1}$ & . & 6548.32 & • & 6572.41 & - & $\begin{array}{c}1.316 \\
\text { increase }\end{array}$ & $\bullet$ & $\begin{array}{r}1.312 \\
\text { increase }\end{array}$ & $\bullet$ \\
\hline$\pi_{R 2}$ & • & 870.25 & $\bullet$ & 877.64 & $\bullet$ & 0 & $\bullet$ & 0 & $\bullet$ \\
\hline$\mu_{f 1}$ & . & 4619.12 & $\bullet$ & 4658.86 & $\bullet$ & $\begin{array}{r}1.822 \\
\text { decrease } \\
\end{array}$ & $\bullet$ & $\begin{array}{r}1.841 \\
\text { decrease } \\
\end{array}$ & $\bullet$ \\
\hline$\mu_{f 2}$ & $\bullet$ & 5306.7 & • & 5320.96 & $\bullet$ & 0 & $\bullet$ & 0 & $\bullet$ \\
\hline
\end{tabular}

Table 1 shows the result of a 0.25 reduction in factory production costs on research variables.

Table 1. shows the result of a 0.25 decrease in $\mathrm{C}_{2} 1$ on the model variables 
As can be seen from Table 4-7, the reduction in factory production costs leads to a reduction in the retail price of the factory that is purchased from the factory because when the retailer receives the goods cheaper than the producer, in order to boost sales, it's about reducing retail prices.

Also, reducing factory production costs would reduce factory sales prices to retailers as well. Finally, reducing production costs at factory 1 will increase the producer's profit, as it reduces costs and increases net income.

Table 2 shows the result of a 0.25 increase in factory production costs on research variables.

Table 2. shows the result of a 0.25 increase in $\mathrm{C} 1$ on the model variables

\begin{tabular}{|c|c|c|c|c|c|}
\hline $\begin{array}{r}\bullet \\
\text { parameters }\end{array}$ & $\begin{array}{lr}\text { First } & \bullet \\
& \text { scenario }\end{array}$ & & $\begin{array}{l}\text { Second } \\
\text { scenario }\end{array}$ & 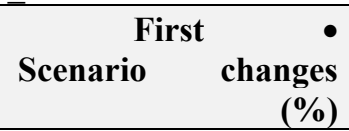 & $\begin{array}{cr}\text { Second } & \bullet \\
\text { Scenario } & \begin{array}{r}\text { changes } \\
(\%)\end{array} \\
\end{array}$ \\
\hline • & 04.375 & 1 & 04.554 & increase $.845^{\bullet}$ & increase .829 \\
\hline • & $\begin{array}{r}\bullet \\
13.857\end{array}$ & 2 & 14.342 & • & • \\
\hline$\bullet$ & $\stackrel{\bullet}{01}$ & 2 & 01.607 & • & $\bullet$ \\
\hline$\bullet$ & 04.375 & 1 & 04.554 & • & • \\
\hline$\bullet$ & $\stackrel{\bullet}{42}$ & 1 & $\begin{array}{r}\bullet \\
42.357\end{array}$ & $\bullet$ & • \\
\hline$\bullet$ & 379.28 & 6 & 402.89 & decrease $.84 \dot{5}$ & decrease .843 \\
\hline$\bullet$ & 70.25 & 8 & 77.64 & • & • \\
\hline$\bullet$ & 658.07 & 4 & 666.72 & increase .81 & increase .75 \\
\hline • & 306.7 & 5 & 320.96 & $\bullet$ & $\bullet$ \\
\hline
\end{tabular}

As can be seen from Table 4-8, the increase in factory production costs leads to an increase in the retail price that it purchases from the factory, because when the retailer receives the goods more expensive than the producer, the proportion To increase retail prices.

Also, an increase in factory production costs will increase the sales price of the factory to retailers as well. Finally, increasing production costs at factory 1 would reduce the producer's profits because it would increase costs and reduce net income for him.

\section{Conclusion}

In fact, in this research, government policy is shaped by considering the requirement for compliance with environmental laws, and so-called green production. In the second scenario, which is a scenario with the provision of green services by producers, considering the green service level parameter, the impact of the green supply chain requirements has been studied in the problem.

Table 5-1 shows the outcomes of the analysis for the first scenario. 
Table 5-1 Outputs of the first scenario

\begin{tabular}{|c|c|c|c|}
\hline amount & $\bullet$ & Symbol & output \\
\hline$\left(a_{11}+b_{11} c_{1}\right) / 2 b_{11}$ & $\bullet$ & $p_{11} \bullet$ & $\begin{array}{l}\text { The optimal amount of the } \bullet \\
\text { first retailer for the product }\end{array}$ \\
\hline$\left(a_{21}+b_{21} \cdot w_{2}\right) / 2 b_{21}$ & $\bullet$ & $p_{21}$ & $\begin{array}{l}\text { Article I. }- \text { The } \\
\text { optimal amount of the } \\
\text { first retailer for the } \\
\text { product }\end{array}$ \\
\hline$\left(a_{22}+b_{22} \cdot w_{2}\right) /\left(2 b_{22}\right)$ & • & $p_{22}$ & $\begin{array}{l}\text { Article II. } \\
\text { Optimum Second Retail } \\
\text { Sales for product } 2\end{array}$ \\
\hline$\left(a_{11}+b_{11} \cdot c_{1}\right) / 2 b$ & 11 & $w_{1} \bullet$ & $\begin{array}{l}\text { Article III. } \\
\text { Optimum } \\
\text { number 1 }\end{array} \quad$ wholesale \\
\hline$\left(a_{21}+a_{22}+b_{21} \cdot c_{1}+b_{22} \cdot c_{2}\right) /\left(2 b_{21}+2\right.$ & & $w_{2} \bullet$ & $\begin{array}{l}\text { Article IV. • Optional } \\
\text { 2nd Wholesaler }\end{array}$ \\
\hline
\end{tabular}

Table 3 shows the outputs from the analysis for the second scenario.

Table 3. Outputs for the second scenario

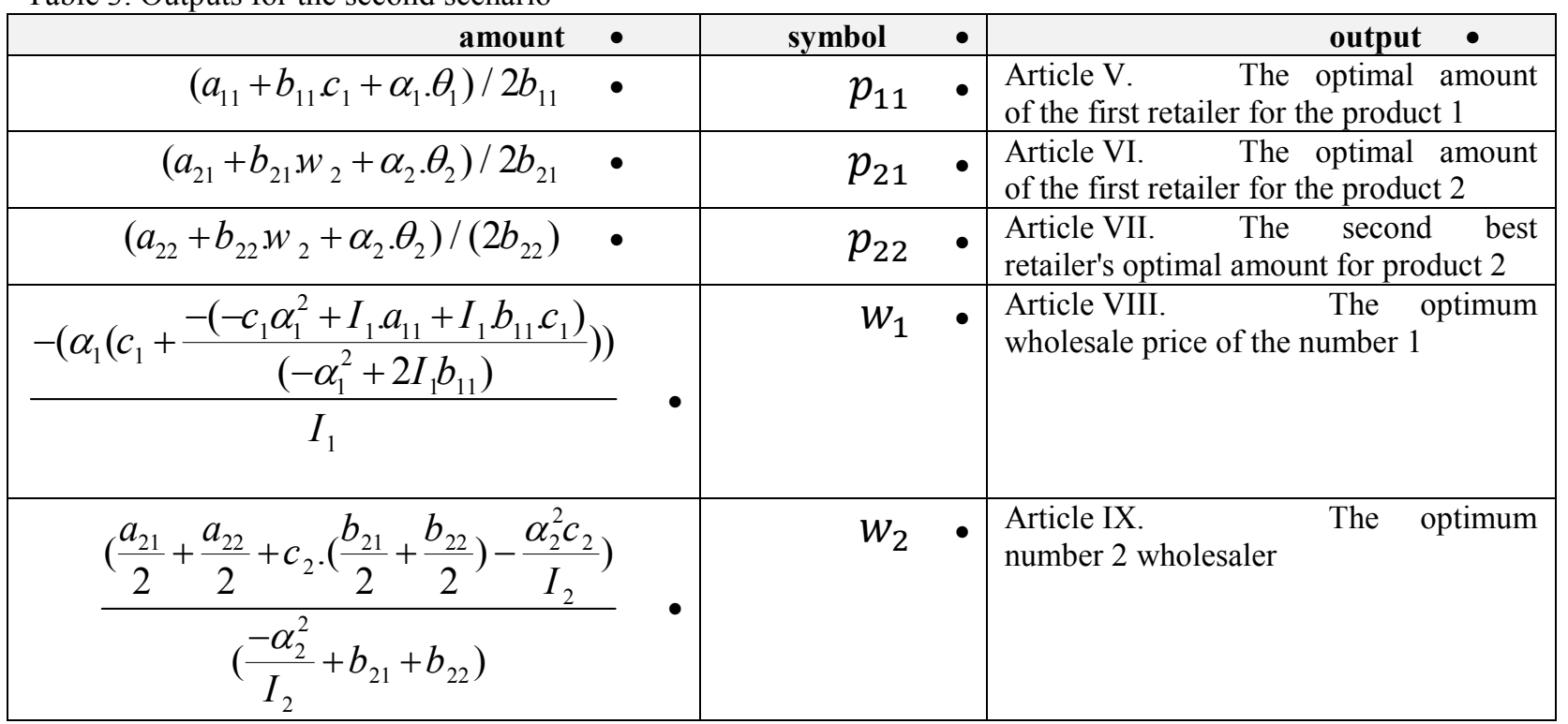

Then the model was solved for different strategies and optimal strategies for each side of the chain were identified. Finally, numerical issues were presented, solved and analyzed in different dimensions.

Finally, the cost sensitivity of the factory was analyzed and the effect of changes in parameters on the variables of the research was measured. The results showed that reducing the production costs of a factory would reduce the retail price that it buys from the factory, because when retailer receives the goods cheaper than the producer does, in order to increase sales by reducing the retail price it takes action. Also, reducing plant production costs will reduce retailers' sales prices. Ultimately, reducing production costs at the factory will increase the producer's profits, as it reduces costs and increases net income.

Similarly, an increase in the cost of producing the factory would increase the retail price that it purchases from the factory, because when it comes to retailing, the goods are more expensive than the producer, they are doing more than increasing retail prices. Also, increasing the cost of producing the factory will increase the sales price of the factory to retailers. Finally, increasing production costs at the plant will reduce the producer's profits, as it increases costs and reduces net income to him.

\section{References}

Chang C-T, Cheng M-C, Ouyang L-Y. (2015). Optimal pricing and ordering policies for non-instantaneously deteriorating items under order-size-dependent delay in payments. Applied Mathematical Modelling;39(2):747-63.

Chao X, Chen H, Zheng S. (2008).Joint replenishment and pricing decisions in inventory systems with stochastically dependent supply capacity. European Journal of Operational Research. 2008;191(1):142-55.

Chen J-M, Lin I-C, Cheng H-L. (2010). Channel coordination under consignment and vendor-managed 
inventory in a distribution system. Transportation Research Part E: Logistics and Transportation Review. 2010;46(6):831-43.

Chen X, Simchi-Levi D (2012) Pricing and inventory management. In: Ozer O, Philips R (eds) The Oxford Handbook of Pricing Management, 1st edn. Oxford University press, New York, pp 784-824.

Chen, Jingxian, et al. (2017). "Price and quality decisions in dual-channel supply chains." European Journal of Operational Research 259.3 (2017): 935-948.

Chung K-J, Lin S-D, Srivastava H. (2012). The complete solution procedures for the mathematical analysis of some families of optimal inventory models with order-size dependent trade credit and deterministic and constant demand. Applied Mathematics and Computation;219(1):142-57.

Chung.K.J, Ting.P.S., (1994). "On replenishment schedule for deteriorating items with time-proportional demand", Production Planning and Control, Vol5, pp. 392- 396.

Ding X-s, Zhang J-h, Chen X. (2012). A joint pricing and inventory control problem under an energy buy-back program. Operations Research Letters. 2012;40(6):516-20.

Fahimnia, B., et al. (2013). "A review and critique on integrated production-distribution planning models and techniques." Journal of Manufacturing Systems 32(1): 1-19.

Gao, J. and D. Wang (2008). Simulation-based optimization and its application in multi-echelon network stochastic inventory system. System Simulation and Scientific Computing, 2008. ICSC 2008. Asia Simulation Conference-7th International Conference on, IEEE.

Geetha.K.V., Uthayakumar.R., (2010). "Economic design of an inventory policy for non-instantaneous deteriorating items under permissible delay in payments", Journal of Computational and Applied Mathematics,Vol223 pp.2492-2505.

GHASEMY YAGHIN, R., TORABI, S. \& FATEMI GHOMI, S. (2012). Integrated markdown pricing and aggregate production planning in a two echelon supply chain: A hybrid fuzzy multiple objective approach. Applied Mathematical Modelling, 36, 6011-6030.

Giri B., Sharma S., (2014), Manufacturer's pricing strategy in a two-level supply chain with competing retailers and advertising cost dependent demand.Economic Modelling, 38, 102-111. 